\title{
CAL and videodisc for lecturers and technophobes*
}

\author{
Graham R. Parslow \\ Senior Tutor, Biochemistry Department \\ T. Robert Haynes \\ Video Services Manager \\ Advisory Centre for University Education \\ University of Adelaide
}

Good computer software lets a novice produce results quickly. The "Q" Instruction package was conceived at Adelaide University as a means to allow teachers without programming experience to generate Computer Assisted Learning (CAL) materials, or even allow lecturers to delegate this chore to their secretaries. It has keen a successful approach and found ready application at TAFE and CAE campuses as well as Universities. The "Q" instruction package which we have developed is now published Internationally by Elsevier-Biosoft (Cambridge UK).

In seeking to exploit the "friendly" interactions possible between students and microcomputers, the aim has been to minimise the computer familiarity expected of both authors and students. Support for optional features, such as complex branching structures and addition of video disc, has been added in a way intended as a natural extrapolation of traditional teaching practices. Teachers often have reserves of true/false or multiple choice questions which are readily adapted to Computer tuition in the "Q" format.

\footnotetext{
* This paper was presented at the EdTech'88 Conference in September 1988 [http:// ascilite.org.au/aset-archives/confs/edtech88/edtech88_contents.html], but was not available in time to be included with the Conference papers.
} 


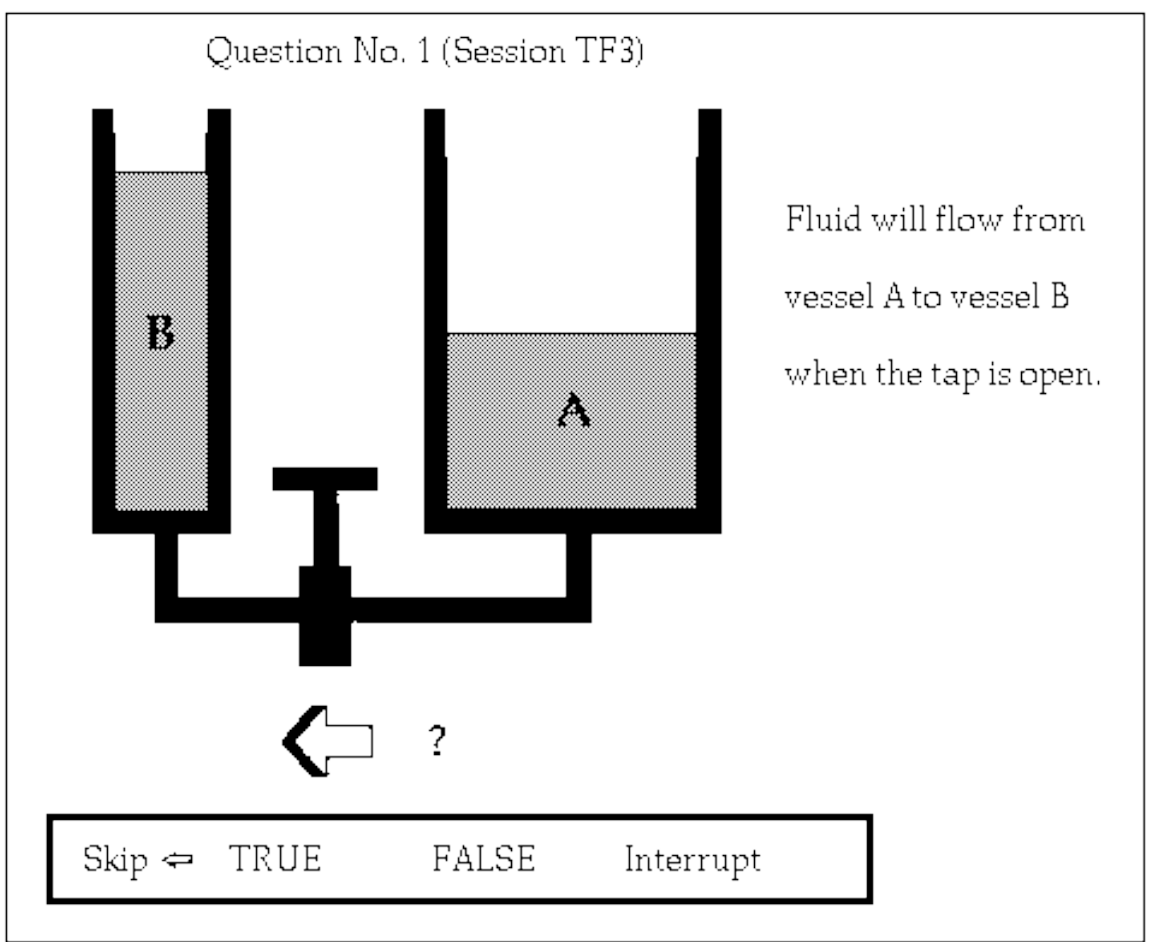

Figure 1: A "Q" tutorial exploits the ability of computers to interact with a student with unfailing patience and consistency.

The following example of a true/false question in "Q" format could have an author rapidly viewing the student-ready product.

It is grammatically correct to say

"The butler could of done the murder."

FALSE

The sentence means to say could have (not could of).

$\&$

Effort is required in defining the educational material rather than in the computer aspects of presentation. The * token used in the above text by an author declares the end of the question and that answer text follows. The ampersand (\&) declares the end of response text and the author can then type the next question or a screen of information. 
The following is a simple multiple choice example:

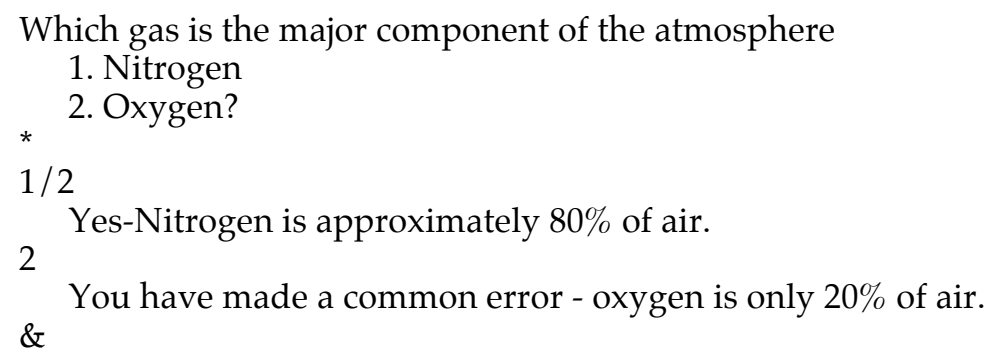

The $1 / 2$ line declares that choice 1 is correct out of a choice limit of 2 . Incorrect responses ( 2 in this simplistic example) can lead to customised messages of explanation or guidance.

Both of the above examples illustrate the teaching of fundamental material which can be particularly suited to computer tuition. The computer is infinitely patient and less intimidating than most human tutors of basic materials. Students can answer with a single keystroke avoiding complex demands on literacy (a notable advantage for students with English as a second language). The ability to give immediate feedback is a substantial educational advantage over the turn-around time of conventional marking.

The "Q" Instruction package also supports free form questions which represent a higher level of demand on student recall. A question might be for example to complete the Wordsworth poem Daffodils

I wandered lonely as a

That floats on __o'er vales and hills,

When all at once I saw a

A host, of golden daffodils.

The students should complete the poem with the words CLOUD, HIGH and CROWD.

Simple lesson material is easy to prepare using the "Q" format and requires only word processing ability. More sophistication can be added by using built-in commands such as JUMP to branch in response to student choice or the score.

Technical subjects require graphic support and "Q" can use Hercules, CGA and EGA resolution graphics on IBM-PC compatible computers (figure 2). Computer graphics however are not a satisfactory solution for showing such demanding subjects as rock formations in our Geology Department or complex pathology specimens in our Medical Faculty. The solution to 
this demand was to produce a videodisc containing much of the established illustrative material used at Adelaide University. "Q" has been a convenient means of enabling lecturers to integrate the Adelaide University videodisc with computer assisted instruction via RS-232 serialport control commands.

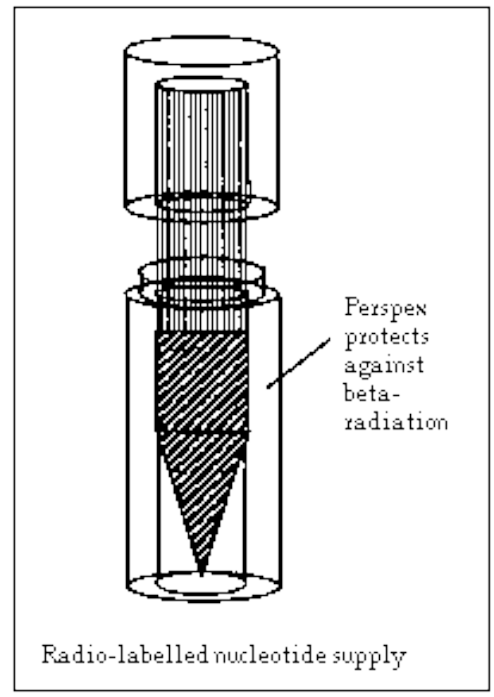

Figure 2: Simple mechanical objects can be conveniently represented by computer graphics. Complex objects require videodisc support.

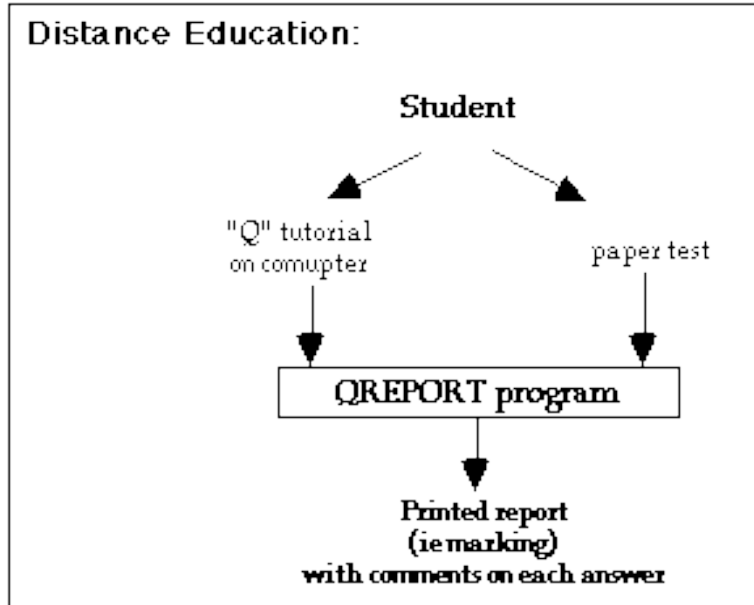

Figure 3: QREPORT was written to provide CAL for in-house students and extended feedback for distance students who take the same material as a paper test. 
The "Q" package has evolved to meet the needs as diverse as those of Medical teachers and Panel-beaters. The rich spectrum of user input has resulted in a package with extensions for distance education (QREPORT, summarised in figure 3) and a data base manager for those with established question banks (QBANK). The guiding principle has been to keep interactions as simple as possible while providing a natural extension of conventional classroom approaches.

We have watched many students in the eighties benefit from having computer assisted material available to them which is customised to their courses. Many commercial "black-box" simulation type packages have restricted utility and often technical errors. Local generation of courseware ensures that it has a "personality" which can be recognised and appreciated by students. We believe that all teachers with a modicum of faith and application can leap long term benefits in applying intelligent technologies to their courses (figure 4).

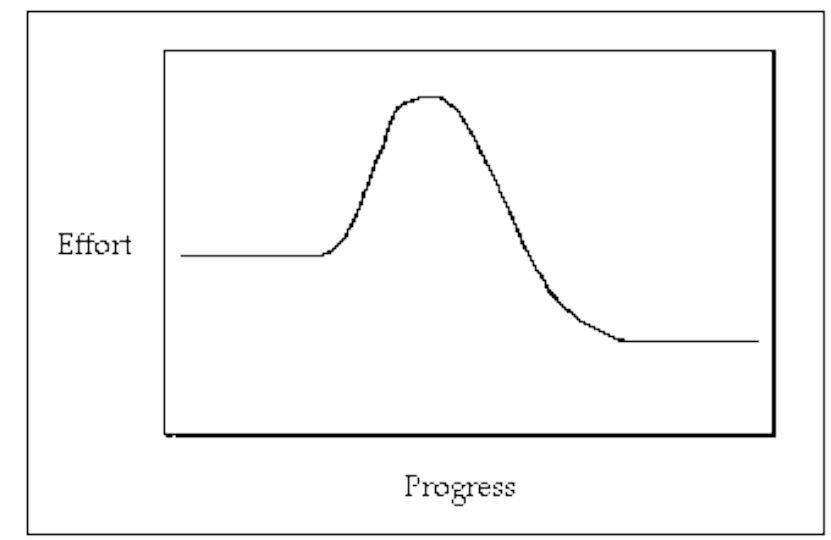

Figure 4: Teachers must expect some short term exertion to establish CAL courses in order to secure long term benefits for both themselves and their students.

Please cite as: Parslow, G. R. and Haynes, T. R. (1988). CAL and videodisc for lecturers and technophobes. Australian Journal of Educational Technology, 4(2), 91-102. http:/ / www.ascilite.org.au/ajet/ajet4/ parslow.html 